\title{
Article \\ Influence of Different Device Structures on the Degradation for Trench-Gate SiC MOSFETs: Taking Avalanche Stress as an Example
}

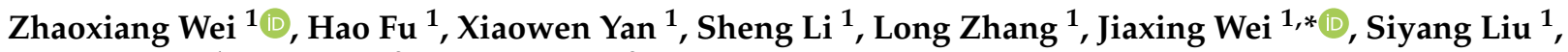 \\ Weifeng Sun ${ }^{1}$, Weili $\mathrm{Wu}^{2}$ and Song Bai ${ }^{2}$ \\ 1 National ASIC System Engineering Research Center, School of Electronic Science and Engineering, \\ Southeast University, Nanjing 210096, China; weizhaoxiang27@163.com (Z.W.); fuhaoseu@163.com (H.F.); \\ yanxiaowen_102@163.com (X.Y.); zzulisheng@163.com (S.L.); xzzlseu_ic@126.com (L.Z.); \\ liusy2855@163.com (S.L.); swffrog@seu.edu.cn (W.S.) \\ 2 Nanjing Electronic Devices Institute, Nanjing 100048, China; wl-wwl@sohu.com (W.W.); \\ songer@gmail.com (S.B.) \\ * Correspondence: jiaxingwei@seu.edu.cn
}

check for updates

Citation: Wei, Z.; Fu, H.; Yan, X.; Li, S.; Zhang, L.; Wei, J.; Liu, S.; Sun, W.; $\mathrm{Wu}, \mathrm{W}$; Bai, S. Influence of Different Device Structures on the Degradation for Trench-Gate SiC MOSFETs: Taking Avalanche Stress as an Example. Materials 2022, 15, 457. https:// doi.org/10.3390/ma15020457

Academic Editor: Fabrizio Roccaforte

Received: 21 November 2021

Accepted: 4 January 2022

Published: 8 January 2022

Publisher's Note: MDPI stays neutral with regard to jurisdictional claims in published maps and institutional affiliations.

Copyright: (C) 2022 by the authors. Licensee MDPI, Basel, Switzerland. This article is an open access article distributed under the terms and conditions of the Creative Commons Attribution (CC BY) license (https:// creativecommons.org/licenses/by/ $4.0 /)$.

\begin{abstract}
The variations in the degradation of electrical characteristics resulting from different device structures for trench-gate $\mathrm{SiC}$ metal-oxide-semiconductor field effect transistors (MOSFETs) are investigated in this work. Two types of the most advanced commercial trench products, which are the asymmetric trench SiC MOSFET and the double-trench SiC MOSFET, are chosen as the targeted devices. The discrepant degradation trends caused by the repetitive avalanche stress are monitored. For the double-trench device, the conduction characteristic improves while the gate-drain capacitance $\left(C_{g d}\right)$ increases seriously. It is because positive charges are injected into the bottom gate oxide during the avalanche process, which are driven by the high oxide electronic field $\left(\mathrm{E}_{\mathrm{ox}}\right)$ and the high impact ionization rate (I.I.) there. Meanwhile, for the asymmetric trench SiC MOSFET, the I-V curve under the high gate bias condition and the $\mathrm{C}_{\mathrm{gd}}$ remain relatively stable, while the trench bottom is well protected by the deep $\mathrm{P}+$ well. However, it's threshold voltage $\left(\mathrm{V}_{\mathrm{th}}\right)$ decreases more obviously when compared with that of the double-trench device and the inclined channel suffers from more serious stress than the vertical channel. Positive charges are more easily injected into the inclined channel. The phenomena and the corresponding mechanisms are analyzed and proved by experiments and technology computer-aided design (TCAD) simulations.
\end{abstract}

Keywords: SiC MOSFET; trench gate; different device structure; degradation; avalanche

\section{Introduction}

With etching, oxidation, and other critical processing technologies becoming more and more mature, SiC metal-oxide-semiconductor field effect transistors (MOSFETs) are gradually applied to power electronic fields to replace traditional silicon power devices [1-4]. Numerous SiC MOSFET products have been pushed into the market [5-7]. Due to the advantages of low-specific ON resistance $\left(R_{\text {onsp }}\right)$, high power density, fast switching speed, and low switching loss, trench-gate SiC MOSFETs are more promising than planar-gate ones [8-10]. However, for the sidewall and the bottom of a trench gate, which suffer from higher electric fields during practical applications, trench-gate SiC MOSFETs are faced with more serious reliability issues when compared with planar-gate devices [11,12].

Infineon and Rohm have released their trench-gate SiC MOSFET products in recent years, which are state-of-art commercial trench-gate devices $[13,14]$. The reliability of them under different stresses, such as the surge current stress, the avalanche stress, and the short-circuit stress, has been well studied [15-26]. Most of the existing articles only report the failure or the degradation mechanism of one single trench-gate device [15-22]. Very 
few of them investigated the failure of both devices at the same time [23-26]. However, no one reported that the disparate device structures would result in different degradations in the device performances, even if they are both trench-gate SiC MOSFETs.

In this work, the variations in the degradation trends resulting from the structure difference between two types of trench-gate devices, which are the double-trench SiC MOSFET produced by Rohm and the asymmetric trench SiC MOSFET produced by Infineon, are investigated in detail. The avalanche stress, which applies load current $\left(\mathrm{I}_{\text {load }}\right)$ and extremely high breakdown voltage (BV) to a device simultaneously and leads to obvious degradation or even damage, is chosen as the targeted stress. It is found that after enduring repetitive avalanche stress, the static and dynamic characteristics of the two trench-gate devices exhibit different degradation trends. With the help of Silvaco TCAD simulations, the dominant mechanism is found and proved by analyzing the physical characteristics of both the devices under avalanche state.

\section{Device Structures and Experiment Conditions}

The cross-sectional schematic diagrams of the double-trench SiC MOSFET (SCT3160KL) and the asymmetric trench SiC MOSFET (IMW120R140M1H) studied in this work are shown in Figure 1a,b. Their rated BV is $1200 \mathrm{~V}$, as listed in Table 1. The rated ON-state resistance $\left(R_{o n}\right)$ and the DC drain current $\left(I_{D}\right)$ of the double-trench SiC MOSFET were $160 \mathrm{~m} \Omega$ and $18 \mathrm{~A}$, while the $\mathrm{R}_{\mathrm{on}}$ and the $\mathrm{I}_{\mathrm{D}}$ of the asymmetric trench SiC MOSFET were $140 \mathrm{~m} \Omega$ and 19 A. They share similar conduction and blocking characteristics.

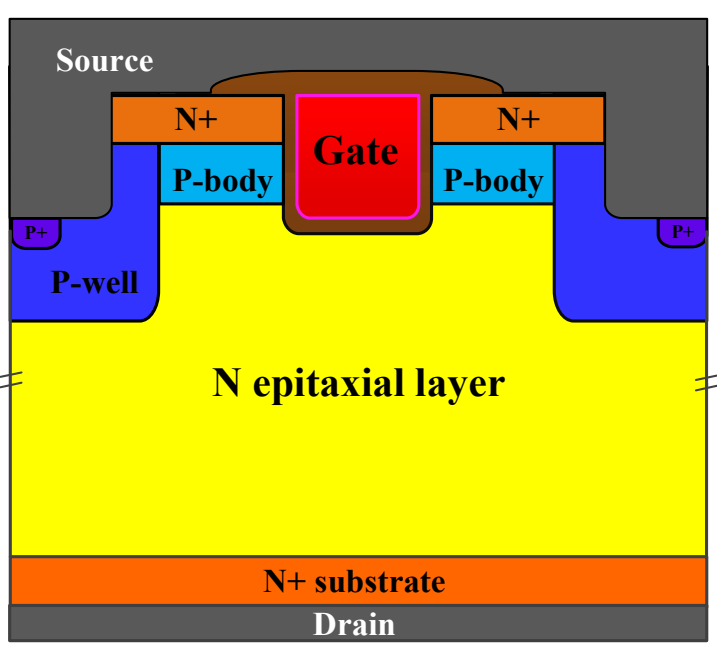

(a)

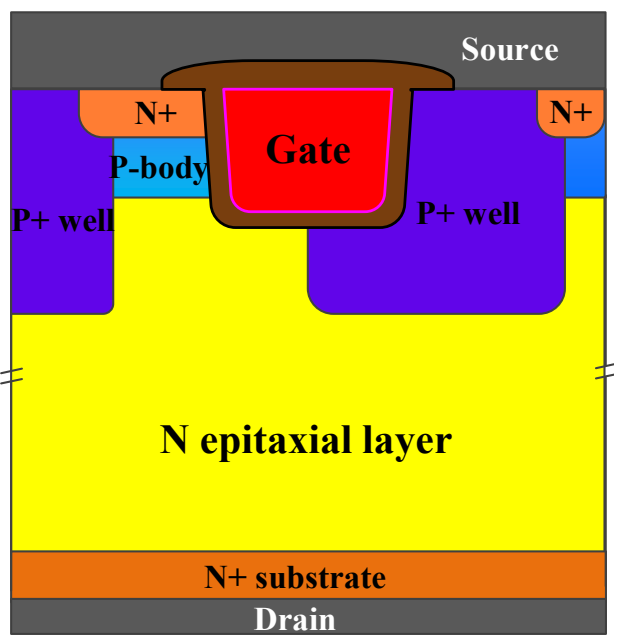

(b)

Figure 1. Schematic cross-sections of different trench-gate SiC MOSFETs. (a) The double-trench SiC MOSFET and (b) the asymmetric trench SiC MOSFET.

Table 1. Device electrical parameters.

\begin{tabular}{ccc}
\hline $\begin{array}{c}\text { Electrical } \\
\text { Parameters }\end{array}$ & $\begin{array}{c}\text { Double-Trench MOSFET } \\
\text { (SCT3160KL) }\end{array}$ & $\begin{array}{c}\text { Asymmetric Trench MOSFET } \\
\text { (IMW120R140M1H) }\end{array}$ \\
\hline $\mathrm{R}_{\mathrm{on}}(\mathrm{m} \Omega)$ & 160 & 140 \\
$\mathrm{I}_{\mathrm{D}}(\mathrm{A})$ & 18 & 19 \\
$\mathrm{BV}_{\mathrm{dss}}=1 \mathrm{uA}(\mathrm{V})$ & 1814 & 1479 \\
\hline
\end{tabular}

The double-trench SiC MOSFET has not only a gate trench to form the two vertical channels but also a source trench. The length and depth of each trench were both $1 \mu \mathrm{m}$. The P-well in the source trench can reduce the bottom electric field of the trench gate. 
For an asymmetric trench $\mathrm{SiC}$ MOSFET, there is only one channel in a single cell. The right corner of the gate is surrounded by the highly doped deep $\mathrm{P}+$ well, which extends to the bottom of the trench gate, protecting the left trench corner where current flows. As shown in Figure 1b, different from the double-trench device, the left trench sidewall of the asymmetric device was parallel to the (11-20) crystal plane. Since the N epitaxial layer is homoepitaxially grown on a $4^{\circ}$ off-axis $4 \mathrm{H}-\mathrm{SiC}(0001)$ substrate, the channel of the asymmetric trench SiC MOSFET is inclined [27]. At the same time, the (11-20) crystal plane provides twice the channel mobility of other crystal planes, which improves the current density of the asymmetric trench SiC MOSFET [27,28].

The cell pitch of the double-trench SiC MOSFET was $3.6 \mu \mathrm{m}$, while that of the asymmetric one was $3.2 \mu \mathrm{m}$. The doping concentrations of the P-body and N-drift region of the double-trench device were set to be $1 \times 10^{17} \mathrm{~cm}^{-3}$ and $8 \times 10^{15} \mathrm{~cm}^{-3}$, while those of the asymmetric one were $1 \times 10^{17} \mathrm{~cm}^{-3}$ and $1 \times 10^{16} \mathrm{~cm}^{-3}$, respectively. All the cell dimensions and the doping concentrations were modified based on the real device structures and the measured characteristics. The simulations performed in this paper were based on the device structures in Figure 1.

Figure 2 expresses the schematic circuit diagram of the avalanche stress system and the oscilloscope waveforms generated by the system on the asymmetric trench SiC MOSFET. A drive circuit controlled the $\mathrm{ON}$ and OFF of the device under testing (DUT). The gate-source voltage $\left(\mathrm{V}_{\mathrm{gs}}\right)$ was set from 0 to $18 \mathrm{~V}$. The DUT was connected in series with an inductor $(\mathrm{L}=1 \mathrm{mH})$. The power supply voltage $\left(\mathrm{V}_{\mathrm{DD}}\right)$ was $100 \mathrm{~V}$. As shown in Figure $2 \mathrm{~b}$, when the gate of the DUT turns ON, the drain-source current $\left(\mathrm{I}_{\mathrm{ds}}\right)$ gradually rises. The rising slope of the current was proportional to the $\mathrm{V}_{\mathrm{DD}}$ and inversely proportional to the inductance value:

$$
\frac{d i}{d t}=\frac{V_{D D}}{L}
$$

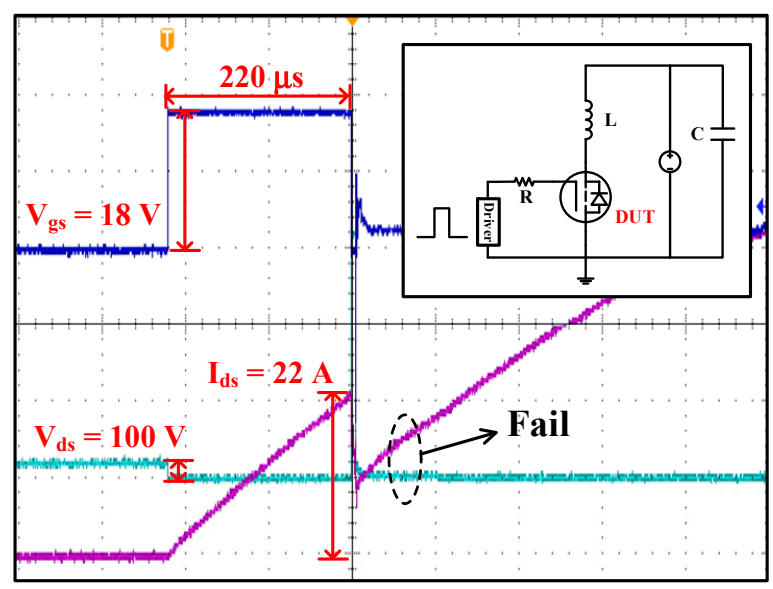

(a)

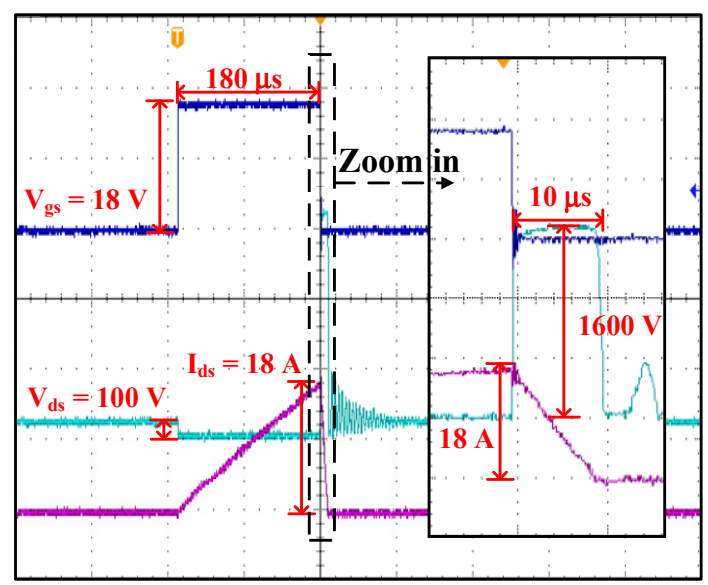

(b)

Figure 2. The avalanche waveforms of the asymmetric trench SiC MOSFET. (a) The failure waveforms and the schematic circuit diagram of the avalanche stress system. (b) The waveforms adopted to stress the device.

When the gate of the DUT turns OFF, the energy stored in the inductor is dissipated on the DUT. At this time, the SiC MOSFET is under the avalanche state. The $\mathrm{V}_{\mathrm{ds}}$ equals to the BV and the current flows through the inductor following the formula:

$$
\frac{d i}{d t}=-\frac{B V-V_{D D}}{L}
$$

When the current in the circuit falls to $0 \mathrm{~A}$, the energy stored in the inductor is completely consumed and the avalanche state of the device ends. 
When applying the avalanche stress on the device and gradually increasing the gate pulse width until it fails, the asymmetric trench SiC MOSFET can endure a peak $\mathrm{I}_{\text {load }}\left(\mathrm{I}_{\text {peak }}\right)$ of $22 \mathrm{~A}$, as shown in Figure 2a. All the three ports of the failed device were short-circuited, indicating that the device dies from thermal runaway [25]. The avalanche waveforms with an $\mathrm{I}_{\text {peak }}$ of $18 \mathrm{~A}$, which is $80 \%$ of $22 \mathrm{~A}$, as shown in Figure $2 \mathrm{~b}$, were adopted here to repetitively stress the asymmetric trench $\mathrm{SiC}$ MOSFET. The gate pulse width was $180 \mu \mathrm{s}$ and the $\mathrm{I}_{\mathrm{ds}}$ increased to $18 \mathrm{~A}$ at a rate of $0.1 \mathrm{~A} / \mu \mathrm{s}$. After that, the gate of the device turns OFF and the device is under the avalanche state while the $V_{d s}$ is kept at $1600 \mathrm{~V}$.

The avalanche-induced failure waveforms of the double-trench SiC MOSFET are shown in Figure 3a. After enduring a 16 A-avalanche stress, the gate leakage current $\left(\mathrm{I}_{\mathrm{gss}}\right)$ is higher than $1 \mu \mathrm{A}$, indicating that the gate failure is the dominant mechanism [18,19]. Obviously, the asymmetric trench $\mathrm{SiC}$ MOSFET can endure much more serious single-pulse avalanche stress than the double-trench one, implying that the asymmetric structure has a better protection effect [25]. Similarly, the avalanche stress with 13 A I peak, which is $80 \%$ the maximum avalanche current the device can endure, was adopted to stress the double-trench SiC MOSFET. The stress waveforms are presented in Figure $3 \mathrm{~b}$. The gate pulse width was $130 \mu \mathrm{s}$. When under the avalanche state, the $\mathrm{V}_{\mathrm{ds}}$ of the double-trench device is $1700 \mathrm{~V}$.

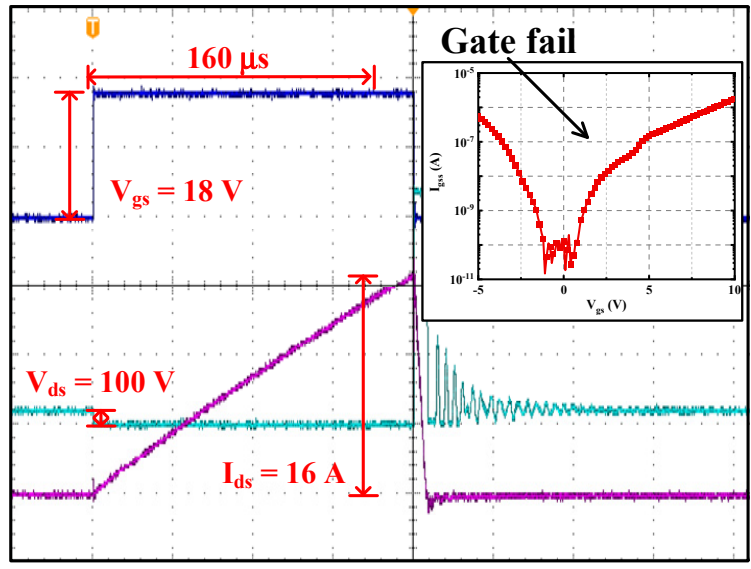

(a)

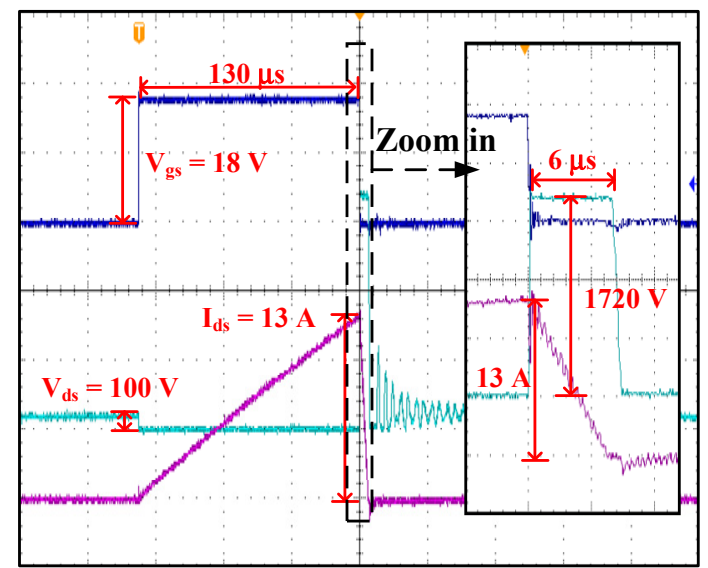

(b)

Figure 3. The avalanche waveforms of the double-trench SiC MOSFET. (a) The failure waveforms. (b) The waveforms adopted to stress the device.

In addition, during the repetitive avalanche stress experiments for both the devices, the duty cycle of all pulses was $0.1 \%$. Wind heat dissipation was also added to suppress the rise in the junction temperature. The repetitive avalanche stress with extremely high voltage and current will lead to the degradation of the devices, which is going to be analyzed in Section 3.

\section{Results and Discussions}

\subsection{Degradation of Electrical Characteristics}

\subsubsection{Asymmetric Trench SiC MOSFET}

After enduring repetitive avalanche stress, the electrical characteristics under different stress cycles were measured and compared. Figure 4 shows the degradation in the threshold voltage $\left(\mathrm{V}_{\mathrm{th}}\right)$ of the asymmetric trench $\mathrm{SiC}$ MOSFET. With the increase of the total stress cycles, the $V_{\text {th }}$ curves shifted to the negative direction. The $V_{\text {th }}$ under the condition of $\mathrm{V}_{\mathrm{ds}}=1 \mathrm{~V}$ and $\mathrm{I}_{\mathrm{ds}}=2.5 \mathrm{~mA}$ is extracted in Figure $4 \mathrm{c}$. After enduring $10 \mathrm{k}$ cycles, the $\mathrm{V}_{\mathrm{th}}$ of the asymmetric device dropped from 4.4 to $3.9 \mathrm{~V}$. In the logarithmic scale, the $\mathrm{V}_{\text {th }}$ at $\mathrm{I}_{\mathrm{ds}}=1 \mathrm{nA}$ was reduced by $1.15 \mathrm{~V}$, as shown in Figure $4 \mathrm{~b}$, which is more obvious than that in the linear scale. This indicates that after enduring the repetitive avalanche stress, the channel of the asymmetric trench SiC MOSFET degrades. 


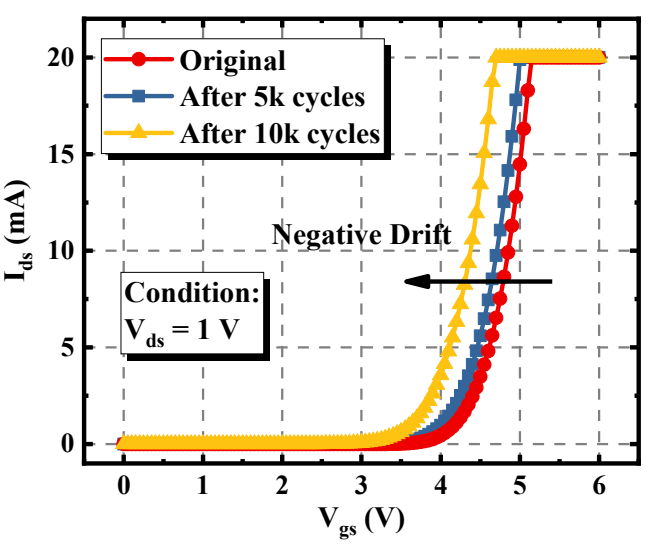

(a)

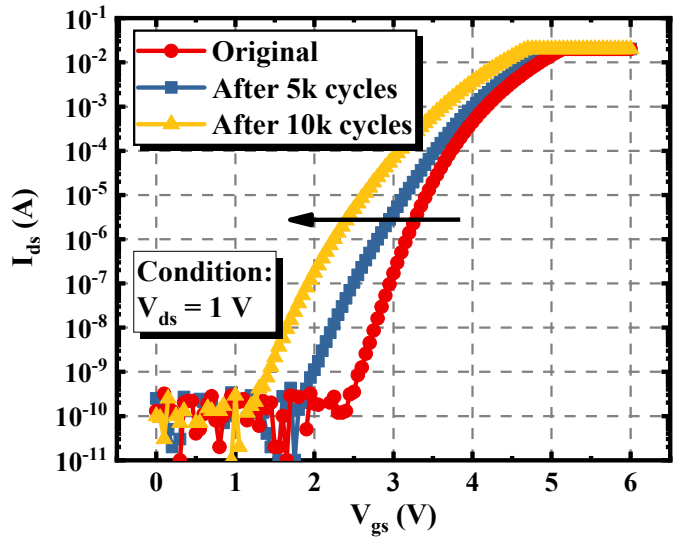

(b)

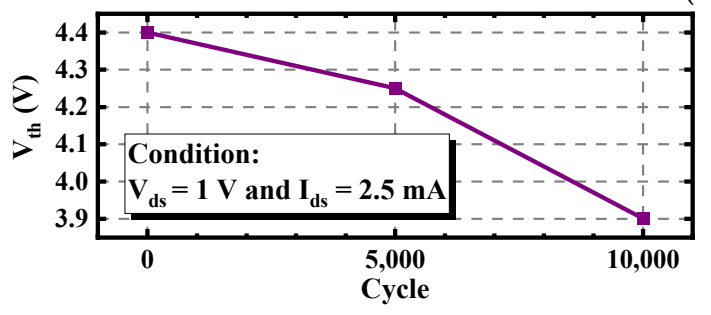

(c)

Figure 4. Variations of the $I_{d}-V_{g}$ characteristic of the asymmetric trench SiC MOSFET under different avalanche stress cycles. (a) $\mathrm{I}_{d}-\mathrm{V}_{\mathrm{g}}$ curves in the linear scale. (b) $\mathrm{I}_{\mathrm{d}}-\mathrm{V}_{\mathrm{g}}$ curves in the logarithmic scale. (c) Extracted degraded $V_{\text {th }}$.

The variations of the $I_{d}-V_{d}$ characteristics of the asymmetric trench device under the conditions of $V_{g s}=6 \mathrm{~V}$ and $V_{g s}=18 \mathrm{~V}$ are plotted in Figure $5 \mathrm{a}, \mathrm{b}$. The $\mathrm{I}_{\mathrm{ds}}$ under the condition of $V_{g s}=6 \mathrm{~V}$ increased due to the decrease of the $V_{\text {th }}$. Meanwhile, the $I_{d}-V_{d}$ curve remained stable when the device was biased under the condition of $\mathrm{V}_{\mathrm{gs}}=18 \mathrm{~V}$. This is because the channel of the device was fully open and the channel resistance was relatively low when compared with the resistances of the junction field effect transistor (JFET) region and $\mathrm{N}$-drift region. This also indicates that the JFET region and drift region of the asymmetric trench $\mathrm{SiC}$ MOSFET are rarely affected by the repetitive avalanche stress.

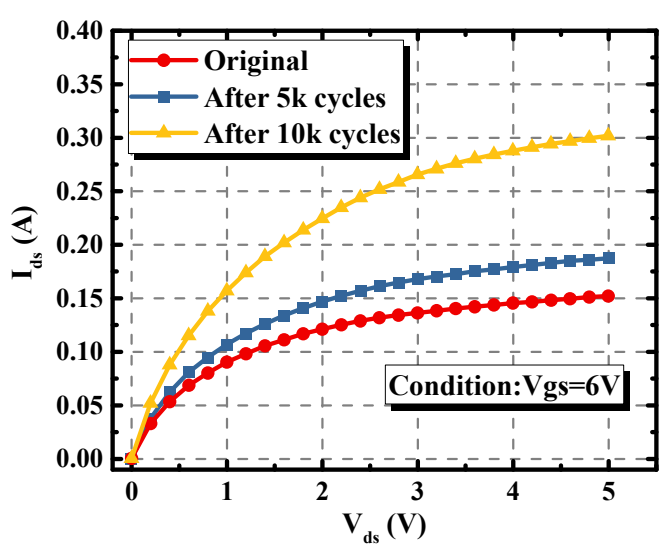

(a)

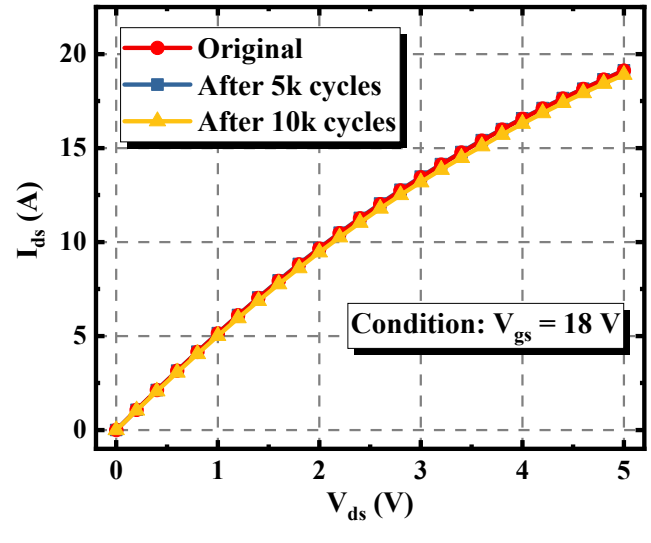

(b)

Figure 5. Variations of the $\mathrm{I}_{d}-\mathrm{V}_{\mathrm{d}}$ characteristic of the asymmetric trench SiC MOSFET under different avalanche stress cycles. (a) $I_{d}-V_{d}$ curves under the $V_{g s}=6 \mathrm{~V}$ bias condition. (b) $I_{d}-V_{d}$ curves under the $\mathrm{V}_{\mathrm{gs}}=18 \mathrm{~V}$ bias condition. 
The variations of the capacitance characteristic of the asymmetric trench device were also measured. As shown in Figure 6, with the increase of the stress cycles, the gate-drain capacitance $\left(\mathrm{C}_{\mathrm{gd}}\right)$ of the device increased slightly. Within 10k cycles, the maximum $\mathrm{C}_{\mathrm{gd}}$ rose from $128 \mathrm{pF}$ to $154 \mathrm{pF}$, equaling to an increment of $20.3 \%$. This is because there were positive charges injected into the left corner and the bottom interface of the gate trench, which will be explained later in Section 3.2.

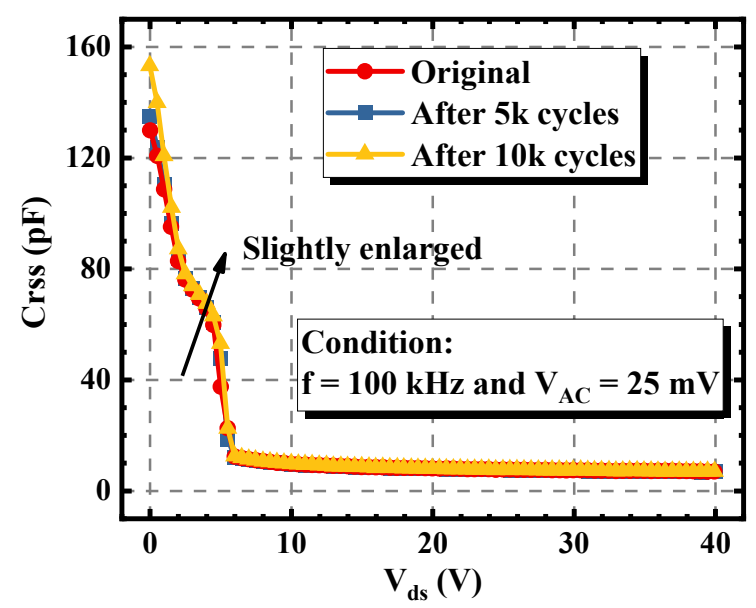

Figure 6. Variations of the $\mathrm{C}_{\mathrm{gd}}$ of the asymmetric trench $\mathrm{SiC}$ MOSFET under different avalanche stress cycles.

\subsubsection{Double-Trench SiC MOSFET}

The repetitive avalanche experiment was also performed on the double-trench $\mathrm{SiC}$ MOSFET. As can be seen in Figure 7 , the $V_{\text {th }}$ of the device only expressed a slight negative shift during the experiment, implying that the channel of the device was rarely degraded, which is quite different from the phenomenon monitored in Figure 4. Meanwhile, as shown in Figure 8, with the increase of the stress cycles, the $I_{d}-V_{d}$ curve under the condition of $\mathrm{V}_{\mathrm{gs}}=18 \mathrm{~V}$ rose significantly. This means that the $R_{\mathrm{on}}$ at $\mathrm{V}_{\mathrm{gs}}=18 \mathrm{~V}$ and $\mathrm{I}_{\mathrm{ds}}=18 \mathrm{~A}$ was decreased by $14 \%$.

The repetitive avalanche experiment was also performed on the double-trench $\mathrm{SiC}$ MOSFET. As can be seen in Figure 7 , the $V_{\text {th }}$ of the device only expressed a slight negative shift during the experiment, implying that the channel of the device was rarely degraded, which is quite different from the phenomenon monitored in Figure 4. Meanwhile, as shown in Figure 8, with the increase of the stress cycles, the $I_{d}-V_{d}$ curve under the condition of $\mathrm{V}_{\mathrm{gs}}=18 \mathrm{~V}$ rose significantly.

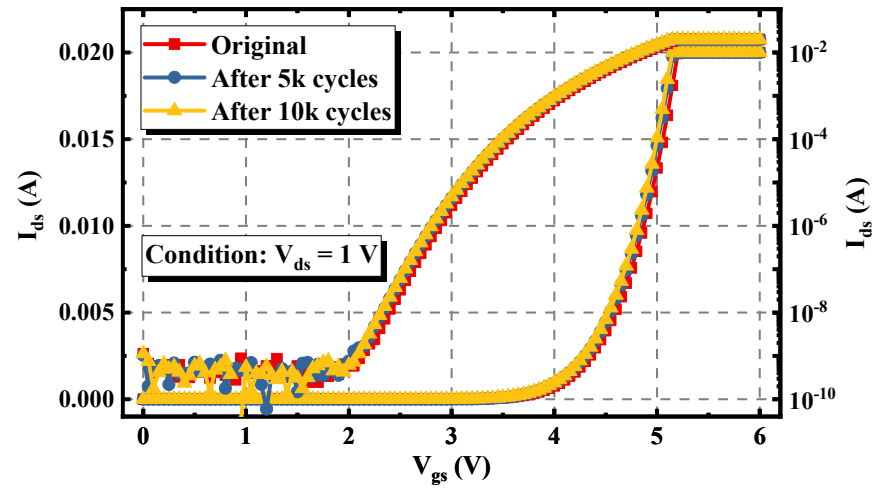

Figure 7. Extracted $\mathrm{I}_{\mathrm{d}}-\mathrm{V}_{\mathrm{g}}$ characteristic of the double-trench SiC MOSFET under different avalanche stress cycles. 


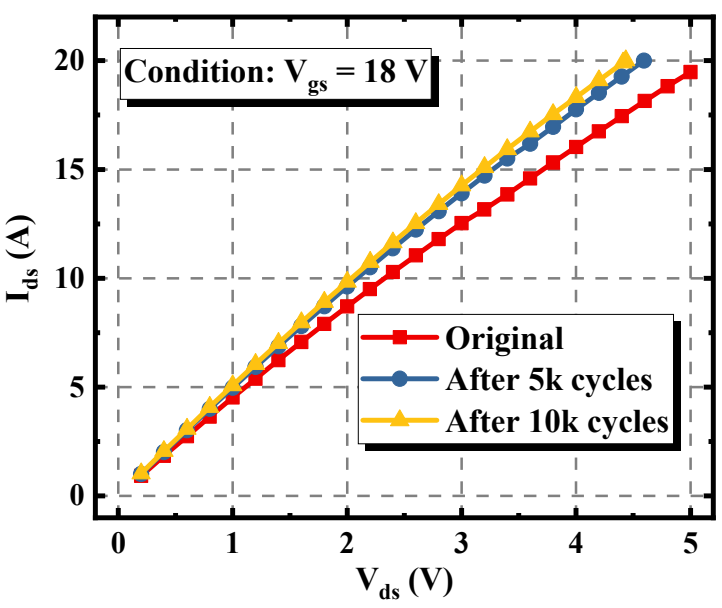

Figure 8. Variations of the $I_{d}-V_{d}$ characteristic at $V_{g s}=18 \mathrm{~V}$ of the double-trench SiC MOSFET under different avalanche stress cycles.

As plotted in Figure 9, after enduring $10 \mathrm{k}$ avalanche stress cycles, the maximum $\mathrm{C}_{\mathrm{gd}}$ of the double-trench device increased from $274 \mathrm{pF}$ to $397 \mathrm{pF}$, equaling to an increment of $44.9 \%$. This obvious degradation resulted from the positive charges injected into the bottom oxide [20]. This indicates that compared with the asymmetric trench SiC MOSFET, much more positive charges were injected into the trench bottom oxide of the doubletrench device during the avalanche process, making the $C_{g d}$ change greatly. At the same time, the positive charges attracted electrons and decreased the resistance of the JFET region. Therefore, the $V_{\text {th }}$ of the double-trench SiC MOSFET was unchanged while the $R_{\text {on }}$ was reduced.

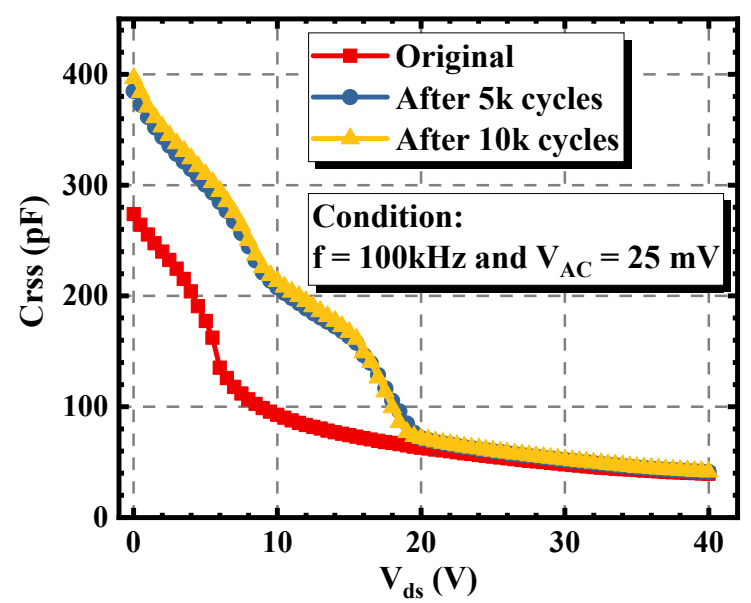

Figure 9. Variations of the $\mathrm{C}_{\mathrm{gd}}$ of the double-trench $\mathrm{SiC}$ MOSFET under different avalanche stress cycles.

\subsection{Simulations and Analysis}

Simulations were then performed to help analyze the various degradation trends between the two types of devices with different structures. Figure 10a reflects the electric field distribution of the double-trench $\mathrm{SiC}$ MOSFET under the avalanche state. The highest electric field was located at the bottom of the source trench, where the avalanche breakdown occurred. Meanwhile, the electric field at the gate trench cannot be ignored. The oxide electric field $\left(\mathrm{E}_{\mathrm{ox}}\right)$ and the impact ionization rate (I.I.) along the gate oxide interface are extracted in Figure 10b. The peak value of the $E_{o x}$ appeared at the bottom, pointing from the semiconductor to the oxide, while the peak I.I. appeared at the corners. This illustrates that the $E_{o x}$ and I.I. at the bottom and corners of the trench together lead to the injection of positive charges into the gate oxide, resulting in an increase in $\mathrm{C}_{\mathrm{gd}}$ and decrease in the 
resistance of the JFET region. There was no I.I. in the channel region of the double-trench device, meaning that the channel was not affected by the stress, which is consistent with the measured data in Figure 7.

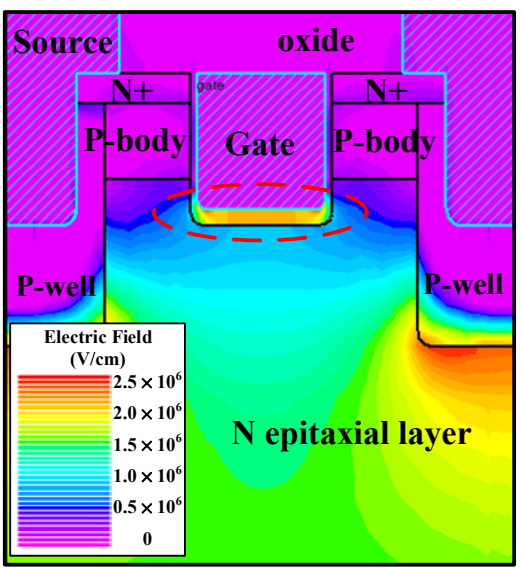

(a)

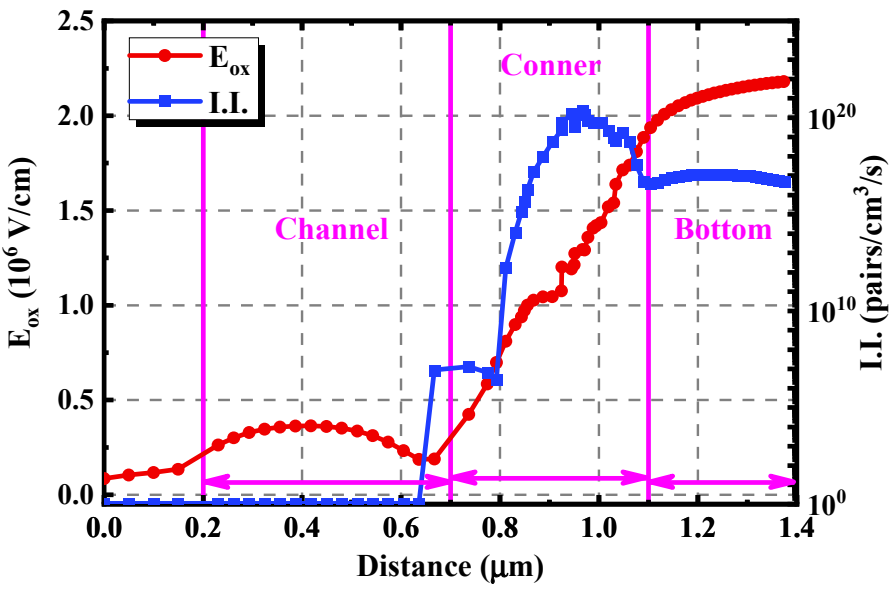

(b)

Figure 10. Physical characteristics of the double-trench SiC MOSFET under the avalanche state. (a) Distribution of the electric field. (b) Extracted $E_{o x}$ and I.I. along the gate oxide interface.

Furthermore, an asymmetric trench SiC MOSFET structure with a vertical channel was built to help analyze the different degradations resulting from the double-trench and the asymmetric structures, ignoring the influence brought by the inclined channel. The physical characteristics of it under the avalanche state are shown in Figure 11. As can be seen in Figure 11a, the peak value of the electric field was located at the bottom of the deep P+ well. Different from the double-trench SiC MOSFET, due to the narrower JFET region, the serious $\mathrm{E}_{\mathrm{Ox}}$ did not appear at the bottom of the trench in the asymmetric device. Comparing Figure $11 \mathrm{~b}$ with Figure $10 \mathrm{~b}$, it can be concluded that both the $\mathrm{E}_{\mathrm{ox}}$ and the I.I. along the trench bottom and the corner of the asymmetric device are much lower than those in the double-trench device. The peak $\mathrm{E}_{\mathrm{ox}}$ fell from $2.18 \times 10^{6} \mathrm{~V} / \mathrm{cm}$ to $8.51 \times 10^{5} \mathrm{~V} / \mathrm{cm}$, decreasing by $61.0 \%$. Meanwhile, the peak I.I. reduced from $1.46 \times 10^{20}$ pairs $/ \mathrm{cm}^{3} / \mathrm{s}$ to $1.70 \times 10^{17}$ pairs $/ \mathrm{cm}^{3} / \mathrm{s}$, equating to a nearly three-orders of magnitude reduction. This demonstrates that the deep $\mathrm{P}+$ well in the asymmetric trench SiC MOSFET can protect the bottom gate oxide well. This is why the double-trench SiC MOSFET shows much more serious degradation in the $C_{g d}$ and the $I_{d}-V_{d}$ curve under the high gate bias condition. Moreover, it is worth noting that there existed a $3.80 \times 10^{7}$ pairs $/ \mathrm{cm}^{3} / \mathrm{s}$ I.I. peak in the channel, even though it was still minor.

The real asymmetric trench SiC MOSFET produced by Infineon adopted the (11-20) crystal plane to form the channel, making the channel inclined. Figure 12 simulates the physical characteristics of the device. The most obvious difference between Figures $12 \mathrm{~b}$ and $11 \mathrm{~b}$ is that a much higher I.I., reaching a peak value of $7.14 \times 10^{14}$ pairs $/ \mathrm{cm}^{3} / \mathrm{s}$, appears at the inclined channel region. This is because the inclined crystal plane made the channel become exposed to the avalanche stress, promoting the positive charges to be injected into the channel oxide. Therefore, the $\mathrm{V}_{\text {th }}$ of the asymmetric trench SiC MOSFET continued to decrease, just as presented in Figure 4. The simulation results are mostly agreeable with the measured data, proving the correctness of the mechanisms discovered and the investigation made in this work. 


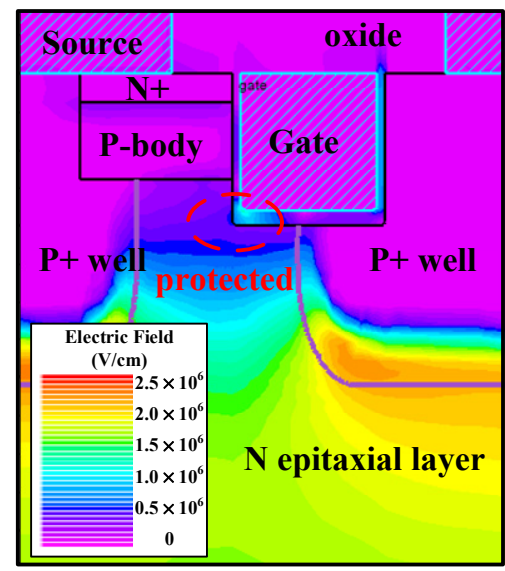

(a)

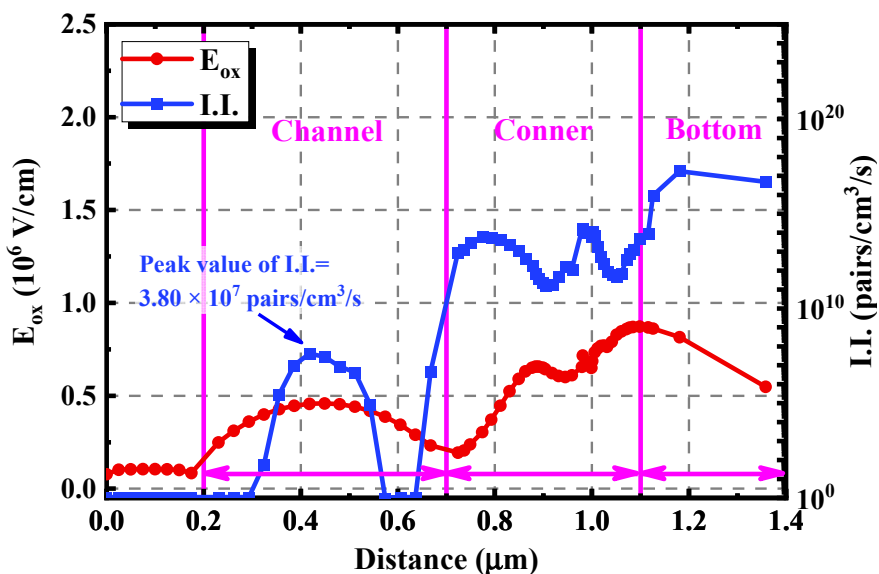

(b)

Figure 11. Physical characteristics of the asymmetric trench SiC MOSFET with a vertical channel under the avalanche state. (a) Distribution of the electric field. (b) Extracted $E_{0 x}$ and I.I. along the gate oxide interface.

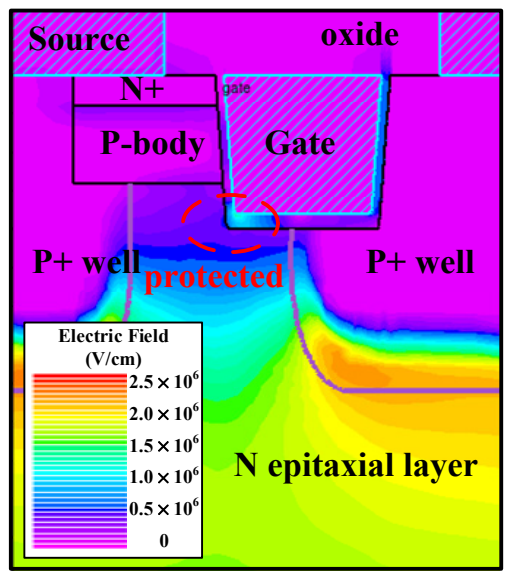

(a)

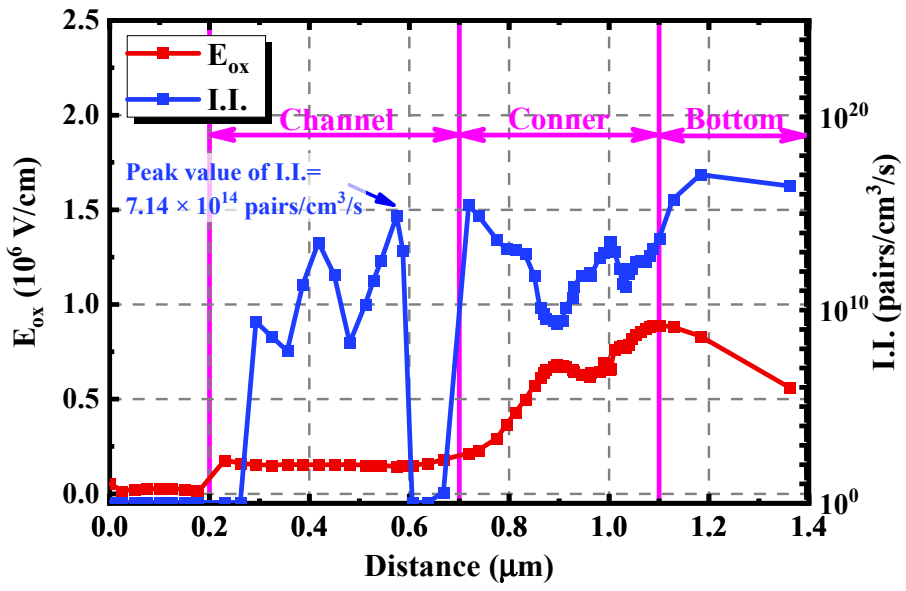

(b)

Figure 12. Physical characteristics of the asymmetric trench SiC MOSFET with an inclined channel under the avalanche state. (a) Distribution of the electric field. (b) Extracted $\mathrm{E}_{\mathrm{Ox}}$ and I.I. along the gate oxide interface.

\section{Conclusions}

Based on the measured discrepant degradation trends between the double-trench $\mathrm{SiC}$ MOSFET and the asymmetric trench SiC MOSFET before and after enduring the repetitive avalanche stress, the mechanisms brought by the different device structures were revealed. On the one hand, since ultrahigh peak values of $E_{\text {ox }}$ and I.I. appeared at the bottom oxide of the double-trench SiC MOSFET under the avalanche state, the positive charges injected there contributed to the obvious decrease of the $R_{o n}$ and to the increase of the $C_{g d}$. These phenomena were not observed in the asymmetric trench device because the deep $\mathrm{P}+$ well protected the bottom gate oxide well. On the other hand, the inclined channel of the asymmetric device attracted a much higher I.I. in the channel region, leading more positive charges to be injected into the oxide there. Hence, the degradation of the $V_{\text {th }}$ of the asymmetric trench $\mathrm{SiC}$ MOSFET was more obvious. The differences in the degradation brought about by the different device structures were summarized and verified. Different from the double-trench SiC MOSFET, the gate oxide at the corner of the trench of the asymmetric trench $\mathrm{SiC}$ MOSFET device was well protected. However, when adopting inclined channel, the channel of the asymmetric device is more vulnerable to damage. 
Therefore, the reliability of both the bottom and the sidewall of the trench needs to be considered in the trench design. It is believed that for these two types of trench-gate $\mathrm{SiC}$ MOSFETs, there also exists different degradation phenomena induced by other repetitive stresses, such as the short-circuit stress, the power cycling stress, and the surge current stress, which will be studied in detail in the future.

Author Contributions: Conceptualization, J.W., Z.W. and H.F.; methodology, J.W., S.L. (Sheng Li), L.Z. and S.L. (Siyang Liu); software, Z.W., H.F. and X.Y.; investigation, J.W., Z.W., H.F. and X.Y.; data curation, Z.W., H.F., S.L. (Sheng Li), and L.Z.; writing-original draft preparation, Z.W.; writing-review and editing, J.W., S.L. (Siyang Liu), W.S., W.W. and S.B.; funding acquisition, J.W., S.L. (Siyang Liu), W.S., W.W. and S.B. All authors have read and agreed to the published version of the manuscript.

Funding: This research study was funded in part by the National Key R\&D Program of China under grant 2020YFF0218501; in part by the National Natural Science Foundation of China under grant 62004037; in part by the Fund for Transformation of Scientific and Technological Achievements of Jiangsu Province under grant BA2020027; in part by the Foundation of State Key Laboratory of Wide-bandgap Semiconductor Power Electronics Devices under grant 2021KF003; and in part by the Distinguished Young Scholars Program of Southeast University.

Institutional Review Board Statement: Not applicable.

Informed Consent Statement: Not applicable.

Data Availability Statement: Data sharing is not applicable for this article.

Conflicts of Interest: The authors declare no conflict of interest.

\section{References}

1. Takeyama, A.; Makino, T.; Okubo, S.; Tanaka, Y.; Yoshie, T.; Hijikata, Y.; Ohshima, T. Radiation Response of Negative Gate Biased SiC MOSFETs. Materials 2019, 12, 2741. [CrossRef] [PubMed]

2. She, X.; Huang, A.Q.; Lucía, Ó.; Ozpineci, B. Review of Silicon Carbide Power Devices and Their Applications. IEEE Trans. Ind. Electron. 2017, 64, 8193-8205. [CrossRef]

3. Mantooth, H.A.; Glover, M.D.; Shepherd, P. Wide Bandgap Technologies and Their Implications on Miniaturizing Power Rlectronic Systems. IEEE J. Emerg. Sel. Top. Power Electron. 2014, 2, 374-385. [CrossRef]

4. Hamada, K.; Nagao, M.; Ajioka, M.; Kawai, F. SiC—Emerging Power Device Technology for Next-Generation Electrically Powered Environmentally Friendly Vehicles. IEEE Trans. Electron Devices 2015, 62, 278-285. [CrossRef]

5. Palmour, J.W. Silicon Carbide Power Device Development for Industrial Markets. In Proceeding of the IEEE International Electron Devices Meeting (IEDM) 2014, San Francisco, CA, USA, 15-17 December 2014; pp. 1.1.1-1.1.8, ISBN 978-1-4799-8001-7.

6. Sabri, S.; Brunt, E.V.; Barkley, A.; Hull, B.; O’Loughlin, M.; Burk, A.; Allen, S.; Palmour, J. New Generation 6.5 kV SiC Power MOSFET. In Proceeding of the IEEE the Workshop on Wide Bandgap Power Devices and Applications (WiPDA) 2017, Albuquerque, NM, USA, 30 October-1 November 2017; pp. 246-250, ISBN 978-1-5386-3117-1.

7. Giovanni, F.D.; Buonomo, S. Latest Developments in Silicon Carbide MOSFETs: Advantages and Benefits vs. Application. In Proceeding of the AEIT Annual Conference 2013, Mondello, Italy, 3-5 October 2013; pp. 1-6, ISBN 978-8-8872-3732-0.

8. Anwar, S.; Wang, Z.J.; Chinthavali, M. Characterization and Comparison of Trench and Planar Silicon Carbide (SiC) MOSFET at Different Temperatures. In Proceeding of the IEEE Transportation Electrification Conference and Expo (ITEC) 2018, Long Beach, CA, USA, 13-15 June 2018; pp. 1039-1045, ISBN 978-1-5386-3048-8.

9. $\mathrm{Na}$, J.; Cheon, J.; Kim, K. 4H-SiC Double Trench MOSFET with Split Heterojunction Gate for Improving Switching Characteristics. Materials 2021, 14, 3554. [CrossRef] [PubMed]

10. Tian, K.; Hallén, A.; Qi, J.; Nawaz, M.; Ma, S.; Wang, M.; Guo, S.; Elgammal, K.; Li, A.; Liu, W. Comprehensive Characterization of the $4 \mathrm{H}-\mathrm{SiC}$ Planar and Trench Gate MOSFETs From Cryogenic to High Temperature. IEEE Trans. Electron Devices 2019, 66, 4279-4286. [CrossRef]

11. Huang, W.; Deng, X.; Li, X.; Wen, Y.; Li, X.; Li, Z.; Zhang, B. Investigation of Surge Current Reliability of $1200 \mathrm{~V}$ Planar and Trench $\mathrm{SiC}$ MOSFET. In Proceedings of the IEEE 15th International Conference on Solid-State \& Integrated Circuit Technology (ICSICT) 2020, Kunming, China, 3-6 November 2020; pp. 1-3, ISBN 978-1-7281-6235-5.

12. Aichinger, T.; Schmidt, M. Gate-oxide reliability and failure-rate reduction of industrial SiC MOSFETs. In Proceedings of the IEEE International Reliability Physics Symposium (IRPS) 2020, Dallas, TX, USA, 28 April-30 May 2020; pp. 1-6, ISBN 978-1-7281-3199-3.

13. Nakamura, T.; Nakano, Y.; Aketa, M.; Nakamura, R.; Mitani, S.; Sakairi, H.; Yokotsujiet, Y. High Performance SiC Trench Devices with Ultra-low Ron. In Proceeding of the IEEE International Electron Devices Meeting (IEDM) 2011, Washington, DC, USA, 5-7 December 2011; pp. 26.5.1-26.5.3, ISBN 978-1-4577-0505-2. 
14. Peters, D.; Siemieniec, R.; Aichinger, T.; Basler, T.; Esteve, R.; Bergner, W.; Kueck, D. Performance and Ruggedness of 1200V $\mathrm{SiC}$-Trench-MOSFET. In Proceeding of the International Symposium on Power Semiconductor Devices and IC's (ISPSD) 2017, Sapporo, Japan, 28 May-1 June 2017; pp. 239-242, ISBN 978-4-88686-096-5.

15. Boige, F.; Richardeau, F. Gate leakage-current analysis and modelling of planar and trench power sic mosfet devices in extreme short-circuit operation. Microelectron. Rel. 2017, 76-77, 532-538. [CrossRef]

16. Wei, J.; Liu, S.; Tong, J.; Zhang, X.; Sun, W.; Huang, A.Q. Understanding Short-Circuit Failure Mechanism of Double-Trench SiC Power MOSFETs. IEEE Trans. Electron Devices 2020, 67, 5593-5599. [CrossRef]

17. Yao, K.; Yano, H.; Tadano, H.; Iwamuro, N. Investigations of SiC MOSFET Short-Circuit Failure Mechanisms Using Electrical, Thermal, and Mechanical Stress Analyses. IEEE Trans. Electron Devices 2020, 67, 4328-4334. [CrossRef]

18. Wei, J.; Liu, S.; Zhao, H.; Fu, H.; Sun, W. Verification of Single-Pulse Avalanche Failure Mechanism for Double-Trench SiC Power MOSFETs. IEEE J. Emerg. Sel. Top. Power Electron. 2021, 9, 2190-2200. [CrossRef]

19. Li, X.; Tong, X.; Hu, R.; Wen, Y.; Zhu, H.; Deng, X.; Sun, Y.; Chen, W. Failure Mechanism of Avalanche Condition for $1200 V$ Double Trench SiC MOSFET. IEEE J. Emerg. Sel. Top. Power Electron. 2021, 9, 2147-2154. [CrossRef]

20. Wei, J.; Liu, S.; Yang, L.; Tang, L.; Lou, R.; Li, T.; Fang, J.; Li, S.; Zhang, C.; Sun, S. Investigations on the Degradations of Double-Trench SiC Power MOSFETs Under Repetitive Avalanche Stress. IEEE Trans. Electron Devices 2019, 66, 546-552. [CrossRef]

21. Wang, Z.; Li, Y.; Sun, X.; Liu, Y.; Zhu, Z.; Ren, N.; Guo, Q. Reliability Investigation on SiC Trench MOSFET under Repetitive Surge Current Stress of Body Diode. In Proceeding of the IEEE Workshop on Wide Bandgap Power Devices and Applications in Asia (WiPDA Asia) 2020, Suita, Japan, 23-25 September 2020; pp. 1-4, ISBN 978-1-7281-5955-3.

22. Fu, H.; Wei, J.; Yan, X.; Zhao, H.; Liu, S. Degradation Investigations on Asymmetric Trench SiC Power MOSFETs Under Repetitive Unclamped Inductive Switching Stress. In Proceeding of the International Symposium on Power Semiconductor Devices and IC's (ISPSD) 2021, Nagoya, Japan, 30 May-3 June 2021; pp. 239-242, ISBN 978-4-88686-422-2.

23. Deng, X.; Li, X.; Li, X.; Zhu, H.; Xu, X.; Wen, Y.; Sun, Y.; Chen, W.; Li, Z.; Zhang, B. Short-Circuit Capability Prediction and Failure Mode of Asymmetric and Double Trench SiC MOSFETs. IEEE Trans. Power Electron. 2020, 36, 8300-8307. [CrossRef]

24. Zhu, Z.; Xu, H.; Liu, L.; Ren, N.; Sheng, K. Investigation on Surge Current Capability of 4H-SiC Trench-Gate MOSFETs in Third Quadrant Under Various VGS Biases. IEEE J. Emerg. Sel. Top. Power Electron. 2020, 9, 6361-6369. [CrossRef]

25. Deng, X.; Zhang, B.; Zhu, H.; Li, X.; Zhou, K. Investigation and Failure Mode of Asymmetric and Double Trench SiC MOSFETs Under Avalanche Conditions. IEEE Trans. Power Electron. 2020, 35, 8524-8531. [CrossRef]

26. Yao, K.; Yano, H.; Iwamuro, N. Investigations of UIS Failure Mechanism in 1.2 kV Trench SiC MOSFETs Using Electro-ThermalMechanical Stress Analysis. In Proceeding of the International Symposium on Power Semiconductor Devices and IC's (ISPSD) 2021, Nagoya, Japan, 30 May-3 June 2021; pp. 115-118, ISBN 978-4-88686-422-2.

27. Siemieniec, R.; Peters, D.; Esteve, R.; Bergner, W.; Kück, D.; Aichinger, T.; Basler, T.; Zippelius, B. A SiC Trench MOSFET concept offering improved channel mobility and high reliability. In Proceeding of the European Conference on Power Electronics and Applications (EPE'17 ECCE Europe) 2017, Warsaw, Poland, 11-14 September 2017; pp. 1-13, ISBN 978-90-75815-27-6.

28. Kimoto, T.; Yoshioka, H.; Nakamura, T. Physics of SiC MOS Interface and Development of Trench MOSFETs. In Proceeding of the IEEE Workshop on Wide Bandgap Power Devices and Applications (WiPDA) 2013, Columbus, OH, USA, 27-29 October 2013; pp. 135-138, ISBN 978-1-4799-1194-3. 